\title{
First in situ observation of Cephalopoda at hadal depths (Octopoda: Opisthoteuthidae: Grimpoteuthis sp.)
}

\author{
Alan J. Jamieson ${ }^{1} \cdot$ Michael Vecchione ${ }^{2}$ \\ Received: 6 March 2020 / Accepted: 7 May 2020 / Published online: 26 May 2020 \\ (c) The Author(s) 2020
}

\begin{abstract}
The Cephalopoda are not typically considered characteristic of the benthic fauna at hadal depths (depths exceeding $6000 \mathrm{~m}$ ), yet occasional open-net trawl samples have implied that they might be present to $8000 \mathrm{~m}$ deep. Previous in situ photographic evidence has placed the deepest cephalopod at $5145 \mathrm{~m}$. The discrepancies between the two have meant that the maximum depth for cephalopods has gone unresolved. In this study we report on unequivocal sightings, by HD video lander, of a cephalopod at hadal depths. The demersal cirrate octopod Grimpoteuthis sp. was observed at both 5760 and $6957 \mathrm{~m}$ in the Indian Ocean. These observations extend the known maximum depth range for cephalopods by $1812 \mathrm{~m}$ and increase the potential benthic habitat available to cephalopods from 75 to $99 \%$ of the global seafloor.
\end{abstract}

\section{Introduction}

The total bathymetric range of marine organisms is often difficult to resolve accurately because sampling effort becomes less frequent with increasing depth. One important group with ambiguous records of maximum depth is the molluscan class Cephalopoda. Establishing the maximum depth of the very mobile cephalopods is further hampered because few bottom trawls have been performed at hadal depths $(>6000 \mathrm{~m})$, and contemporary hadal sampling has favoured baited traps and baited camera systems to which cephalopods, being predatory, are rarely attracted. While the cephalopods are not considered to be characteristic for hadal depths, a few historical reports suggest they may indeed be present below 6000 m (Belyaev 1989). In 1949, in the KurilKamchatka Trench, an octopod was captured by an open trawl that sampled to $8100 \mathrm{~m}$ (Uschakov 1952). Also, an octopod egg chorion from the subfamily Bathypolypodinae,

Responsible Editor: J.-H. Hoving.

Reviewed by M. Guerreiro and an undisclosed expert.

Alan J. Jamieson

alan.jamieson@newcastle.ac.uk

1 School of Natural and Environmental Sciences, Newcastle University, Newcastle Upon Tyne NE1 7RU, UK

2 NOAA National Systematics Laboratory, National Museum of Natural History, Washington, DC 20560, USA which are known to attach their eggs to the seafloor, was found in the intestine of the snailfish Pseudoliparis (Careproctus) amblystomopsis from the same trench at 7210-7230 m (Birstein and Vinogradov 1955) which also indicated a hadal distribution (Akimushkin 1963). Finally, in 1975 a specimen of Grimpoteuthis sp. (Opisthoteuthidae) presumably from $7280 \mathrm{~m}$ was obtained by the American J. E. Pillsbury expedition in the Cayman Trench (Belyaev 1989). Note, however, that the J. E. Pillsbury report was never published, possibly indicating lack of confidence that the octopod was captured at the maximum depth of the open trawl. Grimpoteuthis spp. are known to swim, at least occasionally, far above the bottom. These specimens may, therefore, have been collected during either descent or retrieval of the open trawl nets. The egg could have originated from shallower depths and descended down the trench slopes following detachment; a process that concerned scientists at the time with regards to validating trawl samples (Houot 1972). In the absence of direct in situ observation by submersible, or remote camera, these accounts have, therefore, been considered questionable. Indeed, Hoving et al. (2014) inferred that these findings may be 'biased', which insinuates a shallower origin, or at least lack of unequivocal proof of hadal occurrence. The deepest "unbiased" benthic cephalopod record in the literature is a cirrate octopus that was photographed on the abyssal plains 325 miles off Barbados (Jahn 1971). This was a single photograph of an octopod belonging to the family Cirroteuthidae at a depth of $5145 \mathrm{~m}$. This 50-year-old photograph has, until now, remained the 
deepest unequivocal maximum depth record for the Cephalopoda (Hoving et al. 2014). Octopoda such as these are, however, relatively well known at deep abyssal depths close to this record (e.g. Vecchione 2017).

Generally, the Cephalopoda are restricted to abyssal depths or shallower (ca. $<5000 \mathrm{~m}$ ). The deepest sighting of an incirrate octopod, the 'Casper morphotype', is currently $4290 \mathrm{~m}$; (Purser et al., 2016). The deepest unequivocal record of oegopsid squids to date is a 'bigfin squid' (Family: Magnapinnidae) observed at $4735 \mathrm{~m}$ in the western Atlantic (Vecchione et al. 2001).

Here we report on two direct in situ observations of the cirrate octopod Grimpoteuthis sp. from 5760 and $6957 \mathrm{~m}$ in the Java Trench (Indian Ocean). The former represents a depth extension of $615 \mathrm{~m}$ from that of Jahn (1971) while the latter is the first ever in situ imaging of a cephalopod unequivocally at hadal depth, and extends the deepest reliable record of this class of molluscs by $1812 \mathrm{~m}$.

\section{Materials and methods}

The observational deployments reported here were conducted during the Indian Ocean leg of the Five Deeps Expedition (2018-2019). Three identical autonomous baited camera and trap landers with conductivity, temperature and depth (CTD) sensors were deployed seven times between depths of 5760 and $7176 \mathrm{~m}$ in April 2019 (Fig. 1). The landers, known as Skaff, Flere and Closp were deployed from the support ship DSSV Pressure Drop (Jamieson et al. 2019). The HD cameras (IP Multi SeaCam 3105; Deep Sea Power and Light, US) recorded continuously throughout the deployments and CTD (SBE 49 FastCAT, SeaBird Electronics, US) measurements were taken every one second. The landers were baited with mackerel (Scombridae) and the cameras were positioned $30 \mathrm{~cm}$ above the seafloor looking horizontally across the seafloor.

Mantle length (ML) and total length (TL) were digitally estimated from frame grabs taken when the individuals were in line with the lander bait arm. The bait arm served as a reference scale in the field of view.

\section{Results and discussion}

Cephalopods were observed in two of the seven lander deployments. The depths and locations where cephalopods were seen were $5760 \mathrm{~m}\left(11.2483^{\prime} \mathrm{S} / 114.8800^{\prime} \mathrm{E}\right)$ and $6957 \mathrm{~m}$ (11.1200' S/114.9283' E). The bottom time of the two positive deployments was $6 \mathrm{~h} 41 \mathrm{~min}$ and $4 \mathrm{~h} 59 \mathrm{~min}$ respectively. The environmental conditions were $1.34{ }^{\circ} \mathrm{C}$ and $1.51^{\circ} \mathrm{C}$ respectively with a salinity of 34.7 . The substrata at both locations were soft sediments.

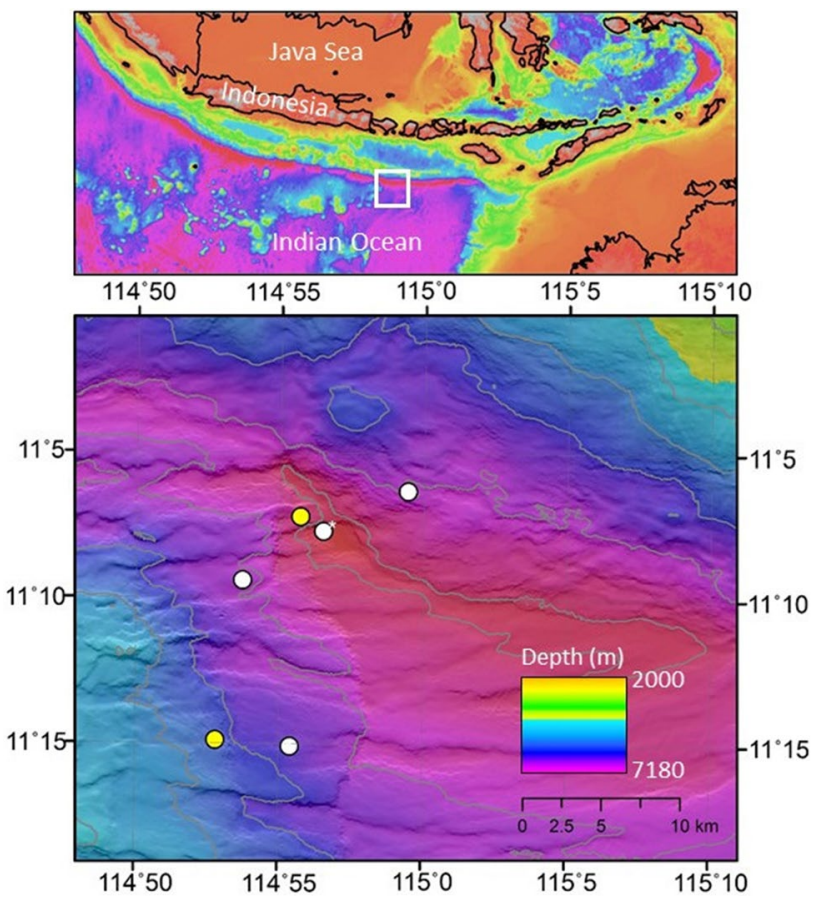

Fig. 1 Sampling location in the Java Trench, East Indian Ocean (white box in top panel). Bottom panel shows all lander deployment sites represented by dots (* indicates two deployments on same site), yellow dots indicate where octopus was observed, white dots are where they were not observed. Grey contours represent $1000 \mathrm{~m}$ contours

At the $5760 \mathrm{~m}$ site, a single Grimpoteuthis sp. (130 mm ML, $430 \mathrm{~mm}$ TL) approached the lander $2 \mathrm{~h} 25 \mathrm{~min}$ after it reached the seafloor (Fig. 2). The octopod spent $23 \mathrm{~min}$ in view, generally not interacting with the bait or lander but apparently foraging around on the seafloor. It exited the field of view for $6 \mathrm{~min}$, returned for $7 \mathrm{~min}$ and exited. It was observed in close proximity to a cusk eel (Bassozetus sp.) and a decapod crustacean (Plesiopeneaus sp,). At $6957 \mathrm{~m}$, a single Grimpoteuthis sp. (110 mm ML, $350 \mathrm{~mm}$ TL) approached the lander 7 min after the lander set down. There it spent $5 \mathrm{~min}$, approaching the lander, then generally not interacting with the bait or lander but rather "foraging" on the seafloor around the surrounding area similarly to the observation described above. It did, however, pick up a munnopsid isopod ( $3 \mathrm{~cm}$ body length), held it for a few seconds, and dropped it back onto the seafloor before exiting the field of view. It was out of view for $21 \mathrm{~min}$ before being observed passing by the lander, several metres away.

We assume here that the two sequential views of cirrates in both observations represent two views of the same animal rather than additional cirrates in the vicinity of the lander. No other cephalopods were observed. As both individuals approached from the horizon of the camera field of view, and in both cases left and returned to the lander, it suggests that artificial illumination was not a deterrent. Furthermore, 
Fig. 2 Frame grabs from the HD video of Grimpoteuthis sp. from a $5760 \mathrm{~m}$, b $6957 \mathrm{~m}$ with c-e showing oral view, and foraging on the seafloor at $6957 \mathrm{~m}$
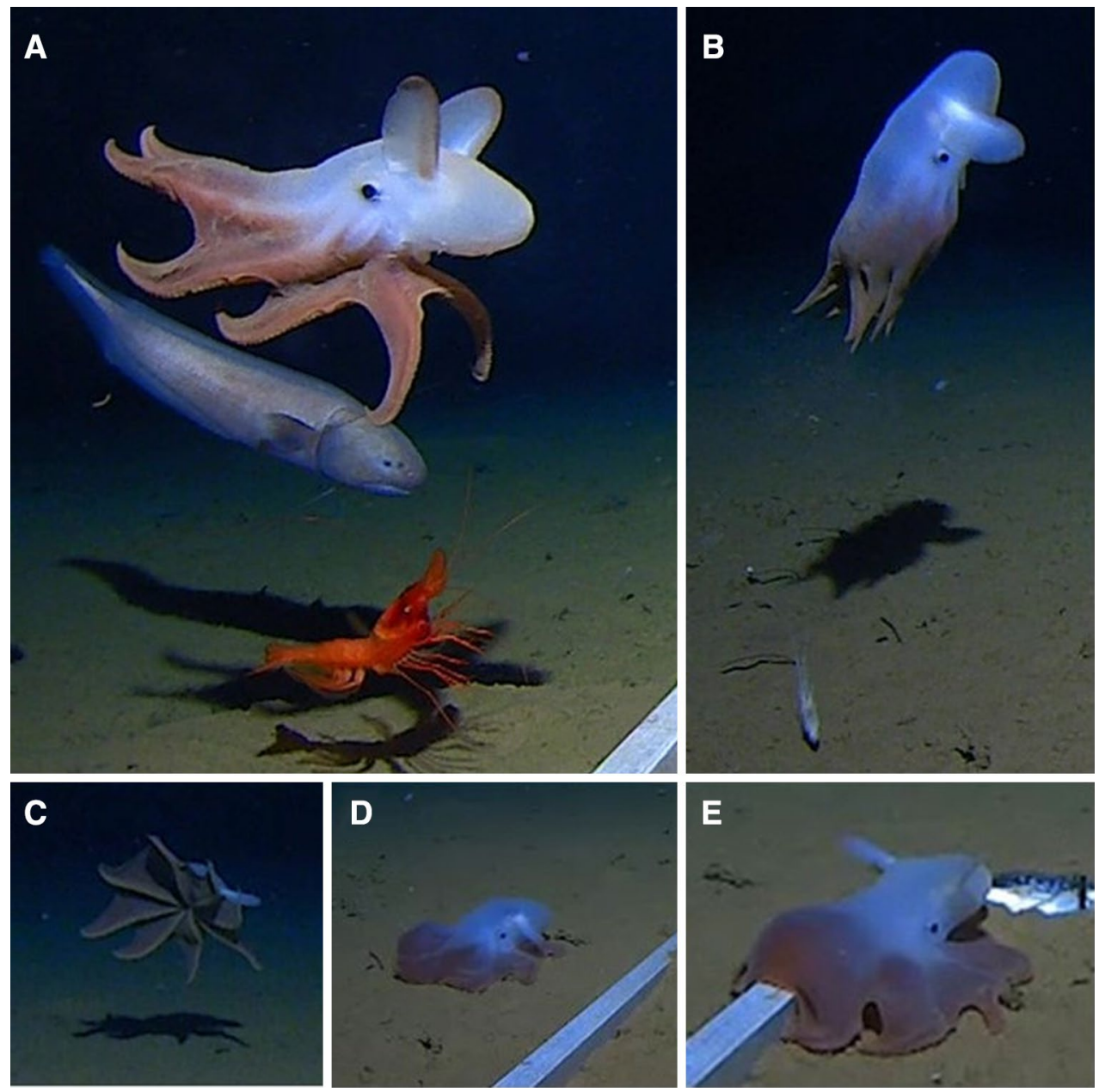

given both individuals had short residence times relative to the duration of the illumination suggests artificial illumination was also not a significant attractant. The behaviour that we presume to be foraging consisted of brief "hops" from place to place, separated by centimetres, on the bottom. Upon contact with the bottom, the arms and webs were spread until the octopod again lifted off the bottom a few seconds later. No observed behaviours suggested that either of these individuals were resting or moribund.

The observations of the cirrate octopod of the genus Grimpoteuthis at $6957 \mathrm{~m}$ extends the reliably documented maximum depth range for cephalopods by $1812 \mathrm{~m}$ (Fig. 3a). Some of the deepest cephalopods captured to date are indeed species of Grimpoteuthis (Collins 2003; Collins and Villanueva 2006), but these new observations extend the range for this genus by over $2000 \mathrm{~m}$ (Fig. 3b). It also unequivocally places a cirrate octopod as a member of the hadal community.

Both cirrate octopods observed in this study are from the same area, therefore it is difficult to confirm whether their hadal presence is global or the result of chance encounter with an abnormally deep population. However, these new in situ observations provide evidence that may substantiate the reports from the former-Soviet trawling campaigns (Uschakov 1952; Birstein and Vinogradov 1955; Akimushkin 1963), which, if are correct, puts the deepest records slightly deeper again at $8100 \mathrm{~m}$. It also provides credence to the Grimpoteuthis sp. from $7280 \mathrm{~m}$ in the Cayman Trench (cited in Belyaev 1989). Indeed, it appears that cephalopods, at least Grimpoteuthis, are perhaps more prevalent in the upper hadal trenches than previously anticipated.

Cirrate octopods are not uncommon in photographic surveys of deep habitats (Roper and Brundage 1972; Vecchione 2017). However, photo-based taxonomy of cephalopods is difficult because many of their generic and specific characters require close morphological examination, often internal, and are not visible in imagery (Vecchione and Roper 1991). The salient point in this study is the unequivocal bathymetric range extension of the molluscan class Cephalopoda, represented by the family Opisthoteuthidae, to well inside the hadal zone - to at least ca. $7000 \mathrm{~m}$. The significance of this bathymetric range extension is perhaps best demonstrated by converting the depth to area of benthic habitat available for these demersal cephalopods. A distribution of 0-5145 m, 
Fig. 3 a Maximum known depth range for cirrates, incirrates, and oegopsids (dark bars) with the cirrate depth range extension from this study (grey bar), plotted against full ocean depth. b maximum capture depths for Grimpoteuthis spp

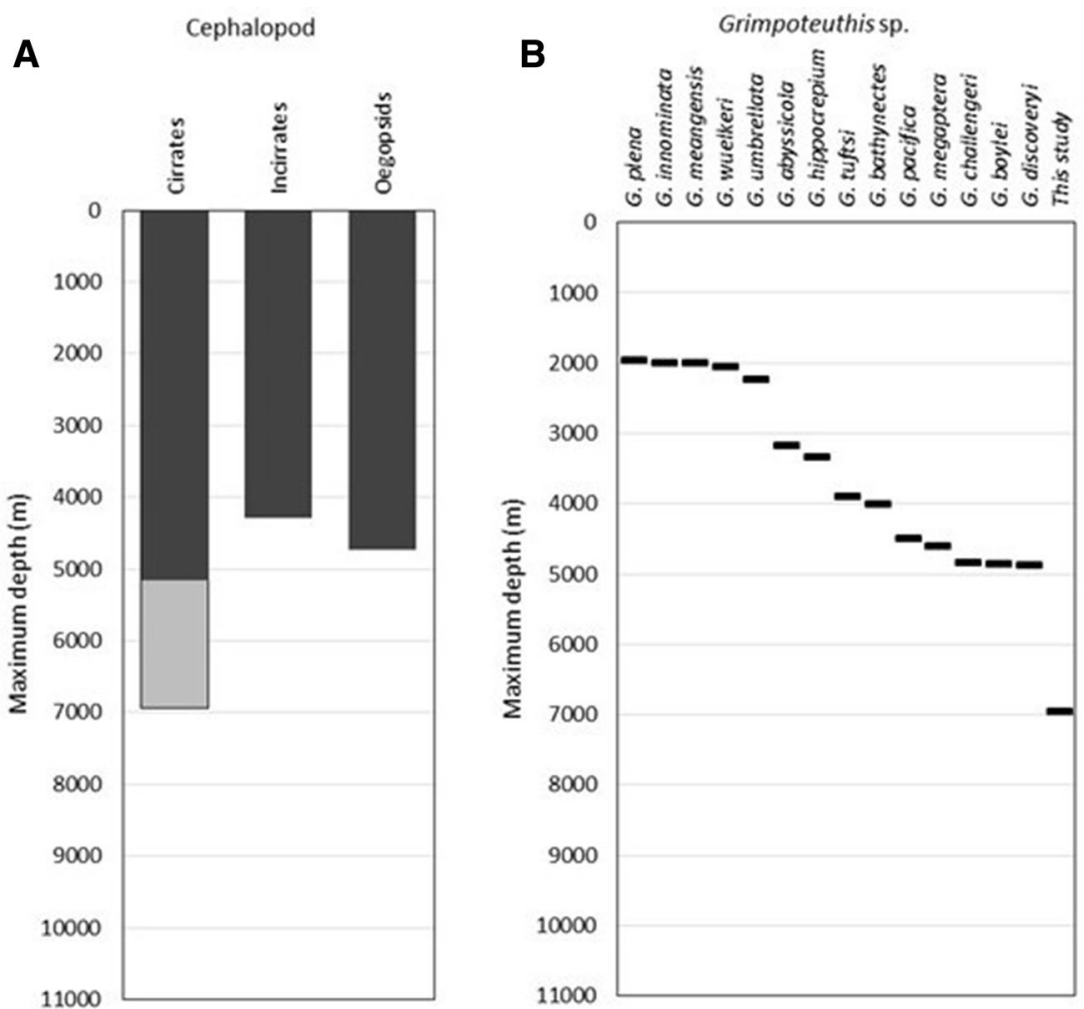

gives octopods access to $75 \%$ of the total ocean floor. This new extension to $7000 \mathrm{~m}$ adds another $24 \%$, bringing the theoretically accessible area of global seafloor to $99 \%$; all but the deepest few thousand metres that diminish exponentially in area with increasing depth (Stewart and Jamieson 2018).

Acknowledgements We thank Victor Vescovo of Caladan Oceanic LLC (US) for creating the Five Deeps Expedition, Rob McCallum and Karen Horlick of EYOS Expeditions (US), Patrick Lahey and Triton Submarines (US), and Captain Stuart Buckle and his crew of the DSSV Pressure Drop. Figure 2 image reproduced with permission from the Discovery Channel 2020.

Funding This study was funded by the Caladan Oceanic LLC as part of the Five Deeps Expedition.

Data availability The data that support the findings of this study are copyright of Discovery Channel 2020 and restrictions apply to the availability of these data, which were used under licence for the current study, and so are not publicly available. Data are however available from the authors upon reasonable request and with permission of Discovery Channel 2020.

\section{Compliance with ethical standards}

Conflict of interest Alan Jamieson declares that he has no conflict of interest. Michael Vecchione declares he had no conflict of interest.

Ethical approval All applicable international, national and/or institutional guidelines for sampling, care and experimental use of organisms for the study have been followed.
Open Access This article is licensed under a Creative Commons Attribution 4.0 International License, which permits use, sharing, adaptation, distribution and reproduction in any medium or format, as long as you give appropriate credit to the original author(s) and the source, provide a link to the Creative Commons licence, and indicate if changes were made. The images or other third party material in this article are included in the article's Creative Commons licence, unless indicated otherwise in a credit line to the material. If material is not included in the article's Creative Commons licence and your intended use is not permitted by statutory regulation or exceeds the permitted use, you will need to obtain permission directly from the copyright holder. To view a copy of this licence, visit http://creativecommons.org/licenses/by/4.0/.

\section{References}

Akimushkin II (1963) Golovonogiye mollyuski morey SSSR [Cephalopoda of the USSR Seas]. Izs-vo AN SSSR, Moscow, p 236

Belyaev GM (1989) Deep-sea ocean trenches and their fauna. Nauka, Moscow

Birstein YA, Vinogradov MY (1955) Observations about the diet of deep-sea fish in the Kuril-Kamchatka Basin. Zool zhurn 34(4):842-849

Collins MA (2003) The genus Grimpoteuthis (Octopoda: Grimpoteuthidae) in the North-east Atlantic, with descriptions of three new species. Zool J Linn Soc-Lond 139:93-127

Collins MA, Villanueva R (2006) Taxonomy. Ecology and behavior of the cirrate octopods. Oceanogr Mar Biol Ann Rev 44:277-322

Houot, G (1972) 20 ans de Bathyscaphe. Arthuad édit., pp 255

Hoving HJT, Perez JAA, Bolstad KS, Braid HE, Evans AB, Fuchs D, Judkins H, Kelly JT, Marian JE, Nakajima R, Piatkowski U, Reid A, Vecchione M, Xavier JCC (2014) The study of deep-sea cephalopods. Adv Mar Biol 67:235-359 
Jahn W (1971) Deepest photographic evidence of an abyssal cephalopod. Nature 232(5311):487-488

Jamieson AJ, Ramsey J, Lahey P (2019) Hadal manned submersible: five deeps expedition explores the deepest point in every ocean. Sea Technol 60(9):22-24

Purser A, Marcon Y, Hoving HJT, Vecchione M, Piatkowski U, Eason D, Bluhm H, Boetius A (2016) Association of deep-sea incirrate octopods with manganese crusts and nodule fields in the Pacific Ocean. Curr Biol 26(24):R1268-R1269

Roper CFE, Brundage WL Jr (1972) Cirrate octopods with associated deep-sea organisms: new biological data based on deep benthic photographs (Cephalopoda). Smithson Contrib Zool 121:1-45

Stewart HA, Jamieson AJ (2018) Habitat heterogeneity of hadal trenches: considerations and implications for future studies. Prog Oceanogr 161:47-65

Ushakov PV (1952) Study of deep-sea fauna. Priroda 6:100-102
Vecchione M (2017) Notes on cephalopods photographed near the bottom in the Clipperton-Clarion Fracture Zone. Mar Biodivers 47(2):307-310

Vecchione M, Roper CFE (1991) Cephalopods observed from submersibles in the western North Atlantic. Bull Mar Sci 49(1-2):433-445

Vecchione M, Young RE, Guerra A, Lindsay DJ, Clague DA, Bernhard JM, Sager WW, Gonzalez AF, Rocha FJ, Segonzac M (2001) Worldwide observations of remarkable deep-sea squids. Science 294:2505-2506

Publisher's Note Springer Nature remains neutral with regard to jurisdictional claims in published maps and institutional affiliations. 